\title{
Fenomena Pekerja Anak (Kasus Pedagang Asongan Anak di Kawasan Ekonomi Khusus Mandalika, Lombok Tengah)
}

\author{
Minawati Anggraini ${ }^{1}$, Siti Nurjannah, Oryza Pneumatica Inderasari \\ Universitas Mataram
}

\begin{abstract}
The phenomenon of child labor food street sellers is a complex problem which currently exists in both. This research is aimed to investigate phenomenon of a child food street in the Mandalika Economic Region and meaning of children's rights for child food street sellers. The research method used is a phenomenology qualitative approach. The main resource of this research is children working as street food sellers. The research results show that being a food street seller is affected by past actions in order to achieve goals. They work almost every day after school time. As street food sellers, most of them define their rights as a child as being fulfilled but some are not. The conclusion that can be drawn from this research is (1) children who become food street sellers have two sets of motives. The first relate to their friends, family economic conditions, up bringing patterns, looseness of school rules, and self-willingness. The secondary motives relate to playing to strengthen social relations, to assist their family's economic circumstances, to bring happiness to their family, to become free from homework, to be independent, and to improve their English. (2) The meaning of children's rights for child food street sellers is the right to play, to receive education, protection, a name, nationality, food, health, recreation, equality, and a role in development. The researcher gives some suggestions such as this study can be a reference for policy-making in the mentoring program.
\end{abstract}

\section{Keywords : Child Labor, A Food Street Seller, Children's Right}

\begin{abstract}
Abstrak
Fenomena pekerja anak sebagai pedagang asongan merupakan masalah yang kompleks. Penelitian ini bertujuan untuk mengetahui fenomena pekerja anak yang bekerja sebagai pedagang asongan souvenir di Kawasan Ekonomi Khusus Mandalika dan makna hak anak bagi pedagang asongan. Metode penelitian yang digunakan adalah dengan pendekatan kualitatif fenomenologi. Sumber utama dalam penelitian ini adalah anak yang bekerja sebagai pedagang asongan. Teknik pengumpulan data yang digunakan adalah triangulasi. Teknik analisis data yang digunakan adalah reduksi data, penyajian data, dan penarikan kesimpulan dari Miles dan Huberman. Hasil penelitian menunjukkan bahwa menjadi pedagang asongan dipengaruhi oleh tindakan masalalu sehingga ada tujuan yang ingin dicapai. Mereka bekerja hampir setiap hari di luar jam sekolah. Sebagai pedagang asongan sebagian besar memaknai haknya sebagai seorang anak dapat terpenuhi adapula yang tidak terpenuhi. Kesimpulan yang dapat diambil dari penelitian ini adalah (1) fenomena pekerja anak yang menjadi pedagang asongan souvenir khas Lombok memiliki dua motif yaitu motif sebab karena faktor teman sebaya, ekonomi keluarga, pola asuh, longgarnya aturan sekolah, dan keinginan sendiri. Motif untuk yaitu bermain sambil mempererat hubungan sosial, membantu ekonomi keluarga, membahagiakan orang tua bebas dari pekerjaan rumah,
\end{abstract}

\footnotetext{
${ }^{1}$ mina.anggraini16@gmail.com
} 
mandiri, dan melatih bahasa inggris. (2) Pedagang asongan memaknai haknya bahwa ada beberapa yang di dapatkan dan ada juga yang tidak didapat diantaranya hak bermain, pendidikan, perlindungan, nama, kebangsaan, makanan, kesehatan, rekreasi, persamaan, peran dalam pembangunan. Berdasarkan penelitian ini peneliti memberi saran yaitu Kajian ini dapat menjadi referensi untuk pengambilan kebijakan dalam program pendampingan.

Kata Kunci : Pekerja Anak, Pedagang Asongan, Hak Anak

\section{Pendahuluan}

Anak-anak sebagai harapan dan penerus bangsa, perlu mendapatkan perhatian yang maksimal baik dari masyarakat maupun dari pemerintah. Sebagai harapan bangsa maka, kesejahteraan anak harus ditingkatkan dan mendapatkan perhatian yang lebih agar mereka dapat menjadi generasi penerus bangsa yang berkualitas. Sehingga diperlakukan secara khusus agar dapat tumbuh dan kembang secara wajar baik fisik, mental maupun rohaninya (Jumadi, 2015).

Survei Pekerja Anak (SPA) yang dilakukan oleh Badan Pusat Statistik(BPS) bekerjasama dengan ILO menemukan dari 58,8 juta anak di Indonesia pada 2009, sekitar 1,7 juta jiwa menjadi pekerja anak. Hasil survey terbaru yang dilakukan ILO pada 2010, di Indonesia masih ada 1,5 juta (4,3 persen) pekerja anak.Menurut Kementerian Ketenagakerjaan (Kemnaker) jumlah pekerja anak atau orang yang bekerja di bawah umur 17 tahun di Indonesia masih tinggi, yaitu sekitar 1,6 juta orang atau orang pada tahun 2017. Sedangkan untuk daerah NTB jumlah pekerja anak sebanyak 5.391 anak pada tahun 2015 (Survey Pekerja Anak Indonesia, ILO, 2009).

Hampir semua studi tentang pekerja anak membuktikan adanya tindakan yang merugikan anak. Para pekerja anak umumnya selain dalam posisi tak berdaya, juga sangat rentan terhadap eksploitasi ekonomi dan merupakan hal yang memprihatinkan karena dunia mereka adalah dunia anak-anak yang seharusnya dimanfaatkan untuk belajar, bermain, bergembira dengan suasana damai dan menyenangkan, dan mendapatkan kesempatan serta fasilitas untuk mencapai citacita sesuai dengan perkembangan fisik, psikologis, intelektual dan sosialnya (Suyanto, 2010). 
Selama ini pemerintah Indonesia telah melakukan langkah-langkah aktif dan strategis untuk menangani masalah pekerja anak. Salah satunya dengan meratifikasi konvensi ILO No. 138 Tahun 1973 dengan UU No. 20 Tahun 1999 mengenai batas usia minimum diperbolehkan untuk bekerja. Selain itu juga UU No.1 Tahun 2000, dan telah diadopsi ke dalam UU No.13 Tahun 2003 konvensi ILO No. 182 tentang ketenagakerjaan mengenai penghapusan bentuk-bentuk pekerjaan terburuk bagi anak (Undang-Undang Perlindungan Anak, 2013).

Keterlibatan pekerja anak baik di sektor formal maupun informal jelas merupakan hal yang memprihatinkan karena sudah semesetinya diminimalisir. Meski telah ada hukum dan aturan yang melarang anak bekerja, ironisnya adalah dalam kenyataannya tetap saja masih bisa ditemui anak-anak yang bernasib malang melakukan aktivitas bekerja. Sebagai sebuah masalah sosial yang multi kompleks, penanganan persoalan pekerja anak bukanlah soal yang mudah (Suyanto, 2013).

Fenomena pekerja anak baik di sektor formal maupun informal masih sering kitatemui diberbagai daerahdi Indonesia.Salah satunya Kabupaten Lombok Tengah, Provinsi Nusa Tenggara Barat di salah satu daerah parwisisata yaitu Kawasan Ekonomi Khusus Mandalika.

Fenomena pekerja anak yang berada disekitar tepi pantai Kuta Kawasan Ekonomi Khusus Mandalika dengan mudah dapat ditemukan anak-anak di bawah umur yang bekerja sebagai pedagang asongan dengan menjual berbagai souviner. Wisatawan domestik maupun mancanegara yang berkunjung ke daerah tersebut tidak lepas dari pengejaran mereka. Mereka menawarkan dan menjajakkan dagangannya kepada siapapun. Terkadang cara mereka menawarkan dagangannya dengan cara yang kurang baik sehingga tidak jarang membuat wisatawan tidak nyaman. Anak-anak yang berjualan tersebut seharusnya sedang belajar, bermain dan beristirahat di rumahnya. Pekerjaan tersebut mereka tekuni secara sendiri-sendiri maupun secara kelompok. Pekerjaan tersebut biasanya dilakukann setelah pulang sekolah dan di hari libur dengan jam kerja yang tidak tentu. Usia anak sekolah dasar yang sudah terbiasa bekerja jauh dari rumahnya tanpa pengawasan langsung oleh orang tuanya. 
Realitas tersebut jelas menempatkan anak pada sisi yang tidak tepat dengan melanggar hak-hak anak secara Internasioanal diakui dalam Konvensi Hak-Hak Anak. Berdasarkan uraian di atas kemudian membuat peneliti tertarik mengkaji karya ilmiah tentang"Fenomena Pekerja Anak (Kasus Pedagang Asongan Anak di Kawasan Ekonomi Khusus Mandalika, Kabupaten Lombok Tengah). Inti pemikiran Schutz adalah bagaimana memahami tindakan sosial melalui penafsiran. Proses penafsiran dapat digunakan untuk memperjelas atau memeriksa makna yang sesungguhnya. Schutz meletakkan hakikat manusia dalam pengalaman subjektif, terutama ketika mengambil tindakan dan mengambil sikap terhadap dunia kehidupan sehari-hari. Melalui tipikasi inilah manusia manusia belajar menyesuaikan diri ke dalam dunia yang lebih luas, dengan juga melihat diri kita sendiri sebagai orang yang memainkan peran dalam situasi tipikal.

Tindakan individu yang dilakukan secara sadar akan senantiasa dapat ditemukan alasan-alasan mengapa seseorang melaukan tindakan (because motive) dan untuk apa ia melakukan tindakan (in order to motive) dalam memahami makna kedua motif ini menjadi objek penting saat melakukan tindakan melihat kembali (refleksi) terhadap peristiwa-peristiwa atau kejadia-kejadian yang telah terjadi pada masa lalu.

Fenomenologi dimaksud untuk mengungkap makna yang dibangun actor terhadap suatu fenomena yang tampak dari tindakan sehari-hari yang dilakukan dengan penuh kesadaran. Dua pertanyaan penting untuk diajukan adalah mengapa suatu tindakan dilakukan dan untuk apa tindakan tersebut dilakukan. Untuk menjawabnya empat hal penting dalam memahami fenomenologi adalah 1) Apa fenomena yang tampak. 2) Fenomena atau kejadian apa yang disadari oleh pelakunya. 3) Mengungkap esensi dari apa yang tampak itu. 4) Kebenaran apa yang diperoleh dari orang pertama. Dalam rangka itu beberapa pertanyaan yang cocok dijadikan panduan dalam menjelasakan fenomenologi adalah. 1) Peristiwa apa yang secara khusus terhubung dengan fenomena yang dikaji. 2) Bagaimanakah peristiwa tersebut mempengaruhi aktor. 3) Bagaimanakah perasaan yang dialami ketika suatu peristiwa terjadi. 4) Bagaimanakah pikiran yang dialami ketika peristiwa tersebut terjadi. 5) Setelah peristiwa terjadi apakah yang berubah karena itu. 6) 
Fenomena Pekerja Anak (Kasus Pedagang Asongan Anak di Kawasan Ekonomi Khusus Mandalika, Lombok Tengah)

bagaimanakah peristiwa yang dialami actor memengaruhi orang lain di sekitarnya.

7) Apakah yang tidak dapat dilakukan dari peristiwa yang terjadi itu. 8) Bagaimanakah lingkungan memberikan respon dari tindakan aktor

\section{Metode Penelitian}

Metode yang digunakan dalam penelitian ini adalah kualitatif deskriptif dengan pendekatan fenomenologi. Lokasi penelitian yang dipilih oleh peneliti yakni di Kawasan Ekonomi Khusus Mandalika. Lingkup analisis dalam penelitian ini adalah pedagang asongan anak, orang tua, LPAD dan petugas keamanan. Penentuan informan penelitian ini dilakukan dengan teknik purposive sampling. Adapun informan penelitian diantaranya pedagang asongan anak, orang tua, satpam dan perangkat desa. Data yang diperlukan berasal dari data primer yang didapatkan langsung dari informan dan data sekunder dari literartur dan buku. Teknik pengumpulan data yakni triangulasi data diantaranya observasi, wawancara dan dokumentasi. Teknik analisis data yang digunakan dalam penelitian ini adalah reduksi data, penyajian data dan penarikan kesimpulan dari Miles dan Huberman.

\section{Hasil dan Pembahasan}

Dalam mengkaji dan menganalisis fenomena pekerja anak yang bekerja sebagai pedagang asongan di Kawasan Ekonomi Khusus Mandalika peneliti menggunakan Teori Fenomenologi Scutz. Menurut Scutz. Di Kawasan Ekonomi Khusus Mandalika tampak adanya pedagang asongan yang tersebar di sepanjang Pantai Kuta dengan membawa dagangan yang berupa gelang, mainan kunci, tas, dompet khas Lombok. Setiap hari dari pagi sampai sore dapat ditemukan anak-anak yang menawarkan dagangannya kepada setiap pengunjung yang datang.

Motif Sebab (because motive) Pedagang Asongan Anak di Kawasan Ekonomi Khusus Mandalika yaitu merujuk pada masa lalu. Tindakan yang dilakukan seseorang pasti memiliki alasan dari masalalunya. Berdasarkan hasil penelitian bahwa (because motive) anak-anak pedagang asongan sebagian besar memutuskan untuk bekerja karena ajakan dari temannya. Bentuk pengaruh dari teman sebaya adalah saling berkaitan antara satu teman dengan teman lainnya, 
anak-anak tersebut saling mengajak dengan teman lainnya. Mereka senang berjualan karena teman-temannya sebagian besar berada di Kawasan Ekonomi Khusus.

Berada di dalam keluarga dengan ekonomi menengah ke bawah akan dirasakan berbeda oleh anak-anak ketika kebutuhan mereka tidak terpenuhi, hal inilah yang menyebabkan anak-anak tersebut bekerja. Dorongan dari orang tua dan mengharapkan uang dari hasil jualan anaknya bisa digunakan untuk memenuhi kebutuhan keluarga. Perlakuan orang tua terhadap anak mempengaruhi anak untuk melakukan suatu tindakan. Hasil penelitian bahwa anak-anak bekerja karena mereka diizinkan oleh orang tuanya untuk bekerja dan dibiarkan begitu saja tanpa ada larangan. Mereka di larang pada waktu tertentu saja seperti ketika cuaca tidak mendukung, ketika bersekolah dan ketika sakit.

Orang tua yang memang aktivitasnya berjualan sejak dulu sambil membawa anaknya ikut berjualan mempengaruhi anak tersebut meniru dan mengikuti tindakan orang tuanya. Aturan sekolah yang longgar membiarkan siswanya untuk bekerja, boleh bekerja dengan syarat tidak mengganggu waktu sekolah dan tidak bekerja ketika ujian. Berdasarkan hasil penelitian bahwa guru dari anak-anak pedagang asongan juga menunjang barang dagangan yang di jual oleh mereka sehingga anakanak tersebut tidak takut untuk melakukan aktivitas berjualan. Anak-anak pedagang asongan juga ingin mencari pengalaman sambil belajar bahasa inggris di pantai. Selain itu mereka juga ingin berlibur menikmati dunia di luar rumahnya.

Motif Untuk (in order to motive) Pedagang Asongan Anak di Kawasan Ekonomi Khusus Mandalika yaitu merujuk pada tindakan di masa yang akan datang yang memiliki tujuan yang telah ditetapkan. Hasil penelitian menunjukkan bahwa para informan memiliki motif untuk bermain sambal mempererat solidaritas social, membantu kebutuhan ekonomi keluarga, kasih sayang anak kepada orang tua, bebas dari pekerjaan rumah, tumbuh menjadi anak yang mandiri dan dapat melatih Bahasa inggris. Di sisi lain informan ingin menikmati dunia anak-anak dengan cara dapat menghasilkan uang di usia yang masih kecil sambil bermain di pusat pariwisata. 


\section{Makna Hak Anak Bagi Pedagang Asongan}

a. Hak bermain

Berdasarkan hasil penelitian bahwa anak-anak pedagang asongan menikmati dunia anak-anaknya dengan berjualan sambil bermain di sekitar pantai bersama dengan teman-temannya.

b. Hak Pendidikan

Berdasarkan hasil penelitian peneliti bahwa ketika hari libur anak-anak pedagang asongan datang ke lokasi jualan dari jam 11 pagi, selain di hari libur yaitu hari biasa untuk sekolah anak-anak pedagang asongan datang sejak siang hari, kecuali dihari libur panjang banyak anak-anak tersebut yang berjualan setiap hari selama mereka libur dari pagi sampai sore bahkan menjelang malam hari.

c. Hak Perlindungan

Berdasarkan hasil penelitian bahwa pedagang asongan anak sebagian ada yang berjualan bersama orang tuanya sembari dijaga, adapula yang datang bersama teman-temannya tanpa pengawasan orang tua. Pedagang asongan anak yyang berjualan bersama orang tua kadang dipantau, akan tetapi tidak sepenuhnya dalam pengawasan orang tua.

d. Hak Makanan

Berdasarkan hasil penelitian bahwa hak makanan, anak-anak pedagang asongan masih medapatkan hak makanannya ketika di rumah, akan tetapi ketika sudah melakukan aktivitas berjualan mereka sendiri yang menunjang makanannya dari hasil berjualan.

e. Hak Kesehatan

Orang tua mereka hanya memperhatikan kesehatan anaknya ketika mengalami sakit, selain itu tidak ada perlakuan khusus untuk hak kesehatan. Berdasarkan hasil observasi bahwa anak-anak pedagang asongan banyak yang tidak menggunakan sandal dan untuk kesehatan fisiknya terlihat lesu dan memperihatinkan karena kelelahan berjalan mencari pembeli dan kepanasan. Pakaian yang dikenakan mereka juga kadang di pakai selama dua hari berturut- 
turut. Akan tetapi mereka tidak terlihat khawatir dengan kesehatannya yang terpenting bisa jualan dan mendapatkan uang.

f. Hak Rekreasi

Hak rekreasi, sebagian besar anak-anak pedagang asongan mendapatkan hak rekreasi dari orang tuanya dengan diajak berlibur ke tempat wisata, sebagian juga ada yang tidak mendapatkan hak rekreasi karena tidak pernah diajak oleh orang tua mereka sehingga rekreasi bisa didapatkan ketika dapat berjualan ke pantai.

g. Hak Persamaan

Berdasarkan hasil penelitian informan merasa bahwa hak atas persamaan masih kurang di dapatkan, selain itu informan lainnya merasa bahwa di dalam keluarganya, di lingkungan tempat mereka jualan bahkan di rumahnya diperlakukan sama saja

h. Hak Peran Dalam Pembangunan

Berdasarkan hasil penelitian mereka dimarah jualan di sekitar pantai karena memang tidak diperbolehkan akan tetapi yang namanya anak-anak masih senang dengan dunia yang tidak mau di atur. Disatu sisi mereka menaati aturan berjualan di sekitar pantai tidak boleh merusak keindahan alam yang ada seperti membawa pasir di laut karena akan merusak terumbu karang.

\section{Kesimpulan}

Berdasarkan hasil penelitian tentang Fenomena Pekerja Anak Kasus Pedagang Asongan di Kawasan Ekonomi Khusus Mandalika dapat disimpulkan sebagai berikut: (1) Motif pedagang asongan anak memiliki dua motif yaitu motif sebab karena faktor teman sebaya, ekonomi keluarga, pola asuh, longgarnya aturan sekolah, dan keinginan sendiri. Motif untuk yaitu bermain sambil mempererat hubungan sosial, membantu ekonomi keluarga, membahagiakan orang tua, mandiri, bebas dari pekerjaan rumah dan melatih berbahasa Inggris. (2) Pedagang asongan memaknai haknya merasa bahwa haknya sebagai seorang anak ada beberapa yang di dapatkan dan ada juga yang tidak di dapat seperti hak bermain, pendidikan, 
Fenomena Pekerja Anak (Kasus Pedagang Asongan Anak di Kawasan Ekonomi Khusus Mandalika, Lombok Tengah)

perlindungan, nama, kebangsaan, makanan, kesehatan, rekreasi, persamaan, peran dalam pembangunan.

\section{Daftar Pustaka}

Afrizal. 2014. Metode Penelitian Kualitatif. Jakarta: PT. Grafindo Persada

Damsar. 2015. Pengantar Teori Sosiologi. Jakarta: Kencana.

Farid, Muhammad dkk. 2018. Fenomenologi: Dalam Penelitian Ilmu Sosial (Edisi Pertama). Jakarta: Pranada Media Group

Hanafi, Ahamad. 2017. Eksploitasi Pekerja Anak di Bawah Umur Sebagai Bentuk Penyimpangan Sosial. Universitas Lampung

https://bit.ly/2Ni6iLD [diakses pada selasa, 2 juli 2019 pukul 08:30 wita]

https://bit.ly/2TKYSBW [diakses pada kamis, 13 juni 2019 pukul 7:30 wita]

https://bit.ly/2zcbgBi [diakses pada jumat, 12 April 2019 pukul 18. 00 wita]

https://bit.ly/2ZdYykl [diakses pada selasa, 2 juli 2019 pukul 22:30 wita]

https://bit.ly/2ZfD4Dr [diakses pada senin, 1 juli 2019 pukul 15:47 wita]

Jumadi, Joko. 2015. Sistem Perlindungan Anak. Mataram: Pustaka Bangsa

Kuswarno, Engkus. 2009. Fenomenologi. Padjajaran: Widya

Menteri Ketenagakerjaan Republik Indonesia. Peta Jalan (Road Map) Menuju Indonesia Bebas Pekerja Anak Tahun 2022

Moleong, Lexy. 2017. Metodelogi Penelitian Kualitatif. Bandung: Remaja Rosdakarya

Ningsih Susanti. 2012. Potret Kehidupan Ekonomi Pedagang Asongan di Fisip UNHAS. Universitas Hasanudin Makassar

O'Donnel, Dan. 2006. Perlindungan Anak. Jakarata: UNICEF

Ritzer, George. 2014. Teori Sosiologi Modern: Edisi Ketujuh. Jakarta: Kencana

Saleh dkk. 2016. Eksploitasi Pekerja Anak Pemulung. Universitas Muhamadiyah Makassar.

Saleh, Saiful dkk. 2016. Eksploitasi Pekerja Anak Pemulung. Universitas Muhamadiyah Makasar

Sanituti, Sri dan Suyanto, Bagong. 2002. Krisis \& Child Abuse. Airlangga: Airlangga University Perss 
Soekanto, Soerjono. 2010. Sosiologi Suatu Pengantar. Jakarta: Rajawali Pers

Sugiyono. 2017. Metode Penelitian Kualitatif, Kuantitatif, dan R\&D. Bandung: Alfabeta

Sulastri, Dewi. 2017. Faktor-Faktor yang Menyebabkan Eksploitasi Pekerja Anak Pada Tambang Emas Tradisional Desa Kelian di Kecamatan Terin. Universitas Mulawarman

Sulistiani dkk. 2014. Fenomena Kehidupan Anak Pekerja Ojek Payung di Malioboro. Universitas Negeri Yogyakarta

Suyanto, Bagong. 2013. Masalah Sosial Anak. Jakarata: Prenada Media Group

Thoib, Ismail \& Azhar Zaini. 2006. Potret Buram Anak Negeri. Mataram: LPA NTB

Undang Undang Nomor 23 Tahun 2002 Tentang Perlindungan Anak

Undang-Undang Perlindungan Anak dan Undang-Undang RI. N0.11 Th 2012 Tentang Sistem Peradilan Pidana Anak. 2013. Permata Press

Wirawan. 2012. Teori Teori Sosial Dalam Tiga Paradigma. Jakarta: Prenamedia Group

Wulandari Silvani. 2016. Motif Makna Diri Pria Penata Rias Di Kota Pekan Baru Dalam Perspektif Fenomenologi. Vol.3 No.2. Riau: Universitas Riau 